\title{
Semi-supervised source localization in reverberant environments using deep generative modeling
}

Bianco, Michael J.; Gannot, Sharon; Fernandez Grande, Efren; Gerstoft, Peter

Published in:

Journal of the Acoustical Society of America

Link to article, DOI:

$10.1121 / 1.5147419$

Publication date:

2020

Document Version

Publisher's PDF, also known as Version of record

Link back to DTU Orbit

Citation (APA):

Bianco, M. J., Gannot, S., Fernandez Grande, E., \& Gerstoft, P. (2020). Semi-supervised source localization in reverberant environments using deep generative modeling. Journal of the Acoustical Society of America, 148(4), 2662 . https://doi.org/10.1121/1.5147419

\section{General rights}

Copyright and moral rights for the publications made accessible in the public portal are retained by the authors and/or other copyright owners and it is a condition of accessing publications that users recognise and abide by the legal requirements associated with these rights.

- Users may download and print one copy of any publication from the public portal for the purpose of private study or research.

- You may not further distribute the material or use it for any profit-making activity or commercial gain

- You may freely distribute the URL identifying the publication in the public portal 
INSIDE LOOK: Samsung Amps Up

Loudspeaker Designs with Simulation

The Journal of the Acoustical Society of America

HOME

BROWSE

MORE $\nabla$

Home > The Journal of the Acoustical Society of America > Volume 148, Issue $4>$ $10.1121 / 1.5147419$
(4)

$$
<\text { PREV }
$$

NEXT >

- No Access

Published Online: 02 December 2020

\section{Semi-supervised source localization in reverberant environments using deep generative modeling}

The Journal of the Acoustical Society of America 148, 2662 (2020);

https://doi.org/10.1121/1.5147419

Michael J. Bianco

- Marine Physical Lab., Univ. of California San Diego, Scripps Inst. of Oceanogr., 9500 Gilman Dr., La Jolla, CA 92037, mbianco@ucsd.edu

Sharon Gannot

more... 


\section{ABSTRACT}

We present a method for acoustic source localization in reverberant environments based on semi-supervised machine learning (ML) with deep generative models. Source localization in the presence of reverberation remains a major challenge, which recent ML techniques have shown promise in addressing. Despite often large data volumes, the number of labels available for supervised learning in reverberant environments is usually small. In semi-supervised learning, ML systems are trained using many examples with only few labels, with the goal of exploiting the natural structure of the data. We use variational autoencoders (VAEs), which are generative neural networks (NNs) that rely on explicit probabilistic representations, to model the latent distribution of reverberant acoustic data. VAEs consist of an encoder NN, which maps complex input distributions to simpler parametric distributions (e.g., Gaussian), and a decoder NN which approximates the training examples. The VAE is trained to generate the phase of relative transfer functions (RTFs) between two microphones in reverberant environments, in parallel with a DOA classifier, on both labeled and unlabeled RTF samples. The performance this VAE-based approach is compared with conventional and ML-based localization in simulated and real-world scenarios.

(C) 2020 Acoustical Society of America.

In the education sector, many heterogeneol

$\bowtie$ IT solutions are in use: Challenge accepted! 